\title{
Clinic, pathologic and molecular landscapes in ultra-young women with breast cancer in the State of São Paulo: a real-world study
}

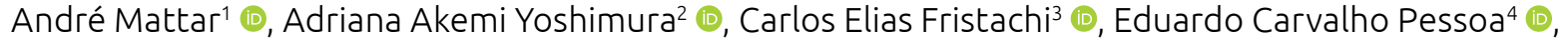

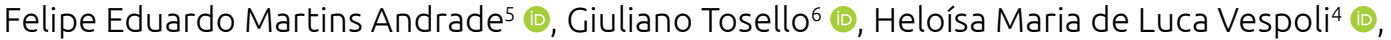

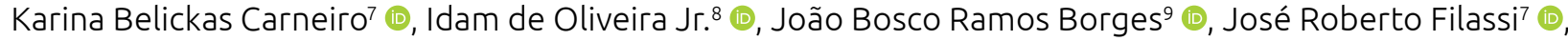

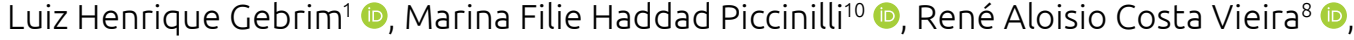 \\ Thamyse Fernanda de Sa Dassie ${ }^{5}$ (), Vicente Tarriconi Junior ${ }^{10}$ (), Alfredo Carlos Simões Dornellas de Barros ${ }^{2 *}$ (1)
}

\section{ABSTRACT}

Introduction: Breast cancer (BC) centers are increasingly attending "ultra-young" women (UYW) patients ( $\leq 30$ years), who usually present aggressive tumors and face specific problems. Objectives: We aimed to examine a multicentric casuistic view, addressing clinicopathological and molecular characteristics of BC, as well as therapeutic measures and oncological outcomes. Methods: A retrospective multicentric observational study of UYW with infiltrating BC was carried out. The patients were treated between the period from January 1991 to December 2019. Clinical, epidemiological, morphological, molecular, therapeutic and outcomes data were collected from the charts. Results: A total of 293 patients were followed for a average period of 34.5 months. Nulliparity was referred by 204 women (75.5\%), of whom 81 (37.1\%) were overweight or obese. Positive family history in first-degree relatives was verified in 25 patients (10.1\%). Only 30 patients underwent genetic tests, which revealed inherited pathogenic mutations in 12 of them (37.5\%). Thirty-two (32) cases were classified as $\mathrm{T}_{1}$ at diagnosis (10.9\%), while "De novo" stage IV was found in 29 patients (9.8\%). Mastectomy was performed in 175 women (70.2\%), quadrantectomy in 46 women (18.4\%), and mammary adenectomies in 28 women (11.2\%), of which 149 cases were reported after neoadjuvant chemotherapy (56.0\%). A total of 111 patients had at least one positive lymph node (47.4\%). The rate of patients with estrogen receptor-negative was 32.7\% and the rate of patients with Human Epidermal Growth Factor Receptor 2-positive (HER2-positive) was 25\%. The frequency of Luminal A neoplasias was 16.6\%, Luminal B/HER2- was 35.9\%, Luminal B/HER2+ was $15.1 \%$, HER2 overexpressed was 9.3\%, and Basal was 22.9\%. Taking into account the outcomes, 173 patients were alive without disease (65.7\%); 23 patients were alive with any form of recurrence (8.7\%); and 67 patients (25.4\%) evolved to BC deaths. Conclusions: It was concluded that UYW with BC are commonly diagnosed at advanced stages, present adverse morphological and molecular parameters, and have unfavorable prognosis.

KEYWORDS: breast neoplasms; ultra-young women; prognosis; therapeutics.

\section{INTRODUCTION}

In recent years, there has been great interest in breast cancer $(\mathrm{BC})$ in young women. Current epidemiological data suggest that a substantial number of young women is affected with this neoplasia, being $\mathrm{BC}$ one of the leading causes of cancer related to deaths in this age range ${ }^{1}$. These patients share some unfavorable biological characteristics, with more aggressive tumors, that are likely to be larger in size when diagnosed, and correlated with higher

${ }^{1}$ Hospital Pérola Byington - São Paulo (SP), Brazil.

${ }^{2}$ Hospital da Beneficência Portuguesa - São Paulo (SP), Brazil.

${ }^{3}$ Instituto Arnaldo Vieira de Carvalho - São Paulo (SP), Brazil.

${ }^{4}$ Hospital das Clínicas de Botucatu - Botucatu (SP), Brazil.

${ }^{5}$ Hospital Sírio Libanês - São Paulo (SP), Brazil.

${ }^{6}$ Hospital Regional de Presidente Prudente - Presidente Prudente (SP), Brazil.

${ }^{7}$ Instituto do Câncer do Estado de São Paulo - São Paulo (SP), Brazil.

${ }^{8}$ Hospital de Câncer de Barretos - Barretos (SP), Brazil.

${ }^{9}$ Faculdade de Medicina de Jundiaí - Jundiaí (SP), Brazil.

${ }^{10}$ Faculdade de Ciências Médicas de Santos - Santos (SP), Brazil.

*Corresponding author: clinab@terra.com.br

Conflict of interests: nothing to declare.

Received on: 04/27/2021. Accepted on: 07/01/2021. 
locoregional recurrence rate and lower survival ${ }^{2-4}$. Young women are often less likely to seek early medical assistance.

In this context, it is necessary clarify what it means the term "ultra-young" women (UYW), since the definition for young woman in $\mathrm{BC}$ scenario varies according to the literature ${ }^{5}$. Considering a specific age related to health problems, such as future reproduction, background mutational process, emotional distress and management dilemmas, we advocate a subdivision of young women with BC into three subgroups: young ( $<40$ years), very young ( $\leq 35$ years), and ultra-young ( $\leq 30$ years).

Specialized centers in BC are increasingly attending UYW. Nevertheless, crucial aspects of the disease in this age range remain controversial and deserve further investigation. Managing patients of this age range, using the knowledge required for older patients, has become more and more difficult. Given these facts, it is meaningful to increase our wisdom on BC in UYW. In this article, we have considered a multicentric casuistic view that has occurred in several BC Centers located in the State of São Paulo, through a retrospective research organized by Brazilian Society of Mastology, São Paulo Region. Clinicopathological and molecular characteristics of $\mathrm{BC}$ in this age group, as well as therapeutic measures and oncological outcomes were addressed.

\section{METHODS}

We conducted a retrospective multicentric observational study with consecutive female ultra-young patients with BC.

\section{Population}

Only patients with infiltrating breast carcinomas aged less than or equal 30 years were included.

Only nine of 23 collaborating centers, invited to participate in this study, sent the completed worksheets to join the research project as follows: Hospital Pérola Byington, Instituto do Câncer do Estado de São Paulo, Hospital Sírio Libanês, Clínica Prof. Alfredo Barros, Hospital de Câncer de Barretos, Faculdade de Ciências Médicas de Santos, Hospital Regional de Presidente Prudente, Hospital das Clínicas de Botucatu and Instituto Arnaldo Vieira de Carvalho.

\section{Data collection}

All patients were treated between January 1991 and December 2019. The following data were recorded: age, body mass index, parity, hormonal contraception use, history of breast/ovarian cancer in the family, pathological tumor category, clinical staging, neoadjuvant and adjuvant treatments, type of surgery, number of positive lymph nodes, multicentricity/multifocality, presence of absence of peritumoral vascular invasion (PVI), histological grade (HG), nuclear grade (NG), and stage categorized according to the American Joint Committee on Cancer (AJCC) staging system.
Immunohistochemical information on estrogen receptor (ER), progesterone receptor (PgR), HER2 and Ki-67 protein were obtained from percutaneous biopsy and/or surgical specimens of patients diagnosed with the disease. ER and PgR were considered positive when the percentage of immunoreactive cells was equal or greater than $1 \%$. The positivity for HER2 was defined as $3+$ staining pattern, or gene amplification by Fluorescence in situ hybridization (FISH). Ki-67 protein was expressed in percentage of stained cells. The assessments were made by the local pathology laboratory in accordance with American Society of Clinical Oncology/College of American Pathologists (ASCO/ CAP) recommendations.

We have classified the cases into five molecular subtypes, akin to modified recommendations of St. Gallen Consensus $(2013)^{6}$ :

- Luminal A-like: ER+ ( $\geq 10 \%), \operatorname{PgR}+(\geq 10 \%)$, HER2-, Ki-67 $\leq 20 \%$; - Luminal B-like HER2-: ER+ $(\geq 10 \%)$, HER2-, PgR $(<10 \%)$ or Ki-67 $\geq 20 \%$;

- Luminal B-like HER2+: ER+ ( $\geq 10 \%)$, HER2+, any Ki-67, any PgR;

- HER2 overexpressed: HER2+ non luminal (ER < 10\%);

- Triple negative: ER- (< 10\%), PgR- $(<10 \%)$, HER2-.

\section{Statistical analysis}

Frequency of parameters were estimated. Statistical analyses were performed using a 0.05 P-value, calculated by the $\chi^{2}$ test. The software IBM SPSS Statistics 25 was used for the analysis.

\section{Ethical aspects}

The research protocol was approved by the Ethics Committee of the Hospital Pérola Byington, which was managed by the Study Coordinator Center (number 3.001.256), and later approved by the Committees of the Collaborating Centers. An informed consent waiver was approved for all anonymous data retrospectively collected.

\section{RESULTS}

The population-based study included 293 patients up to 30 years old - that is, patients between the ages of 19 and 25 years (mean age $=27.3$; median $=28$ ). It shows the distribution of age at diagnosis in three categories as shown in Figure 1: 19-20, 21-25 and 26-30 years. They were followed by a median time of 41.5 months (1.5-207.0), with a median time of 34.5 months.

Body mass indexes are shown in Table 1. It is worth to point that $37.1 \%$ of the patients were overweight or obese.

Taking into consideration the reproductive factors, it was informed that $41.3 \%$ of the patients were current or past users of hormonal contraceptive (data available from 237 patients). Nulliparity was referred by 204 women (75.5\%); parity 1-2 by 64 women (22.9\%); and parity 3-4 by 28 women (10.3\%) (data available from 207 patients). 
We were able to collect data about family history in 246 cases. Positive family history in first-degree relatives was verified in 25 patients (10.1\%), of whom 21 informed the corresponding relative's age at diagnosis: $\leq 30$ years in two patients (9.5\%); > 30 and $\leq 40$ years in 10 patients $(47.6 \%)$; $>40$ and $\leq 50$ years in 5 patients $(23.8 \%)$; and $>50$ years in 4 patients (19.0\%). A total of 66 patients $(26.8 \%)$ reported a family member with BC. Only thirtytwo patients (10.9\%) underwent multigene panel testing, of whom inherited pathogenic mutations were found in 12 of them (37.5\%).

It is known that in most of the younger women the diagnosis is done by finding a lump. Remarkably in this casuistic view, locally advanced tumors were detected in $54.3 \%$ of cases. Detailed information about tumor sizes at diagnosis were listed as shown in Table 2. Clinical axillary lymph nodes evaluation in 283 cases revealed: $\mathrm{N}_{0}$ in 99 cases $(34.9 \%) ; \mathrm{N}_{1}$ in 121 cases $(42.7 \%)$; $\mathrm{N}_{2}$ in 53 cases (18.7\%); and $\mathrm{N}_{3}$ in 10 cases (3.5\%). Clinical staging is showed in Figure 2, being evident high frequency of later stages. Twentynine patients presented systemic metastases and were classified

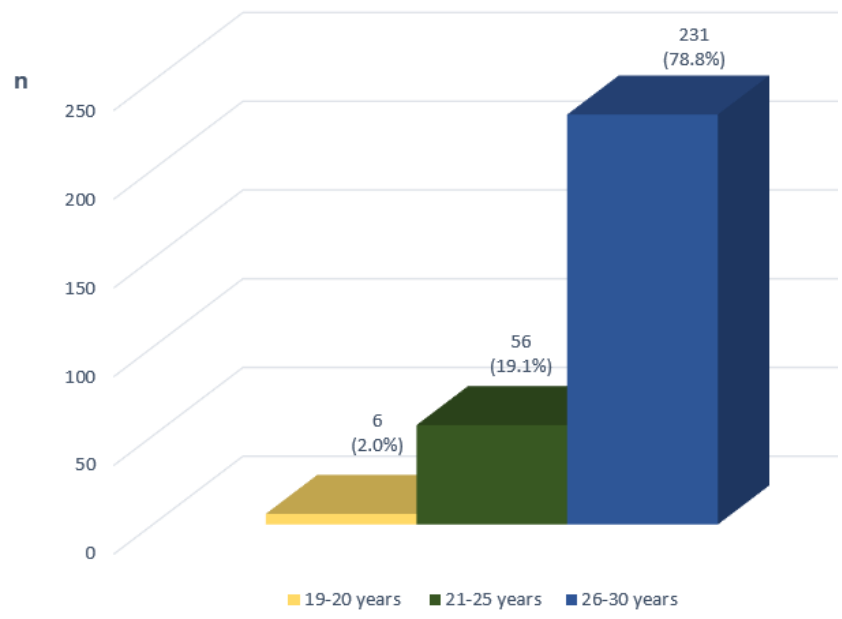

Figure 1. Age ranges of the 293 ultra young patients.

Table 1. Body mass indexes*.

\begin{tabular}{l|c|c|c}
\multicolumn{1}{l|}{$\begin{array}{l}\text { Age range } \\
<18.5\end{array}$} & underweight & 21 & $\%$ \\
\hline $18.5-<25$ & normal & 116 & 53.2 \\
\hline$\geq 25-<30$ & overweight & 53 & 24.3 \\
\hline$\geq \mathbf{3 0}$ & obese & $\mathbf{2 8}$ & $\mathbf{1 2 . 8}$ \\
\hline
\end{tabular}

*Without information: 75.

Table 2. Tumor size at diagnosis*.

\begin{tabular}{l|c|c} 
& $\mathbf{n}$ & $\%$ \\
\hline $\mathrm{T}_{1}$ & 32 & 11.8 \\
\hline $\mathrm{T}_{2}$ & 92 & 33.9 \\
\hline $\mathrm{T}_{3}$ & 86 & 31.6 \\
\hline $\mathrm{T}_{4}$ & $\mathbf{6 2}$ & $\mathbf{2 2 . 7}$ \\
\hline
\end{tabular}

*Without information: 21. as "De novo" stage IV (9.8\%). The metastases sites were: bone eight cases (27.5\%); lung - five cases (17.2\%); liver — four cases (13.7\%); and multiple - 12 cases (41.3\%).

Among 266 patients with attainable information, 149 of them (56.0\%) received neoadjuvant chemotherapy, of whom $118(79.1 \%)$ presented favorable clinical response (partial or total). In our study no patients underwent neoadjuvant hormone therapy.

Of all the types of local surgery performed in 249 patients with available data, mastectomy was performed in 175 patients $(70.2 \%)$; breast conservative surgery was performed in 46 cases (18.4\%); and unilateral or bilateral mammary adenectomies was performed in 28 patients $(11.2 \%)$, as shown in Figure 3.

Sentinel node biopsy was performed in 78 patients $(27.5 \%)$, and axillary dissection was made in case of involvement, and 205 were treated with up-front lymph node axillary dissection (72.4\%). Information on lymph nodes involvement was obtained from 234 patients and Table 3 discriminates the results. It is worth mentioning that about half of the patients received neoadjuvant chemotherapy, likely generating interference in these findings.

Reliable information about morphologic neoplasia subtype were obtained in 260 cases. Invasive carcinoma $\left(\mathrm{N}_{0} \mathrm{~s}\right)$ was observed in 243 patients (93.4\%), infiltrative lobular was extremely rare, being found in three patients (1.5\%), and other subtypes were seen in 14 patients (5.3\%).

Tables 4 and 5 shows, respectively, histopathological and immunohistochemical characteristics found in percutaneous biopsies before neoadjuvant chemotherapy or in the surgical specimens of the 192 patients of whom it was possible to obtain detailed information to classify the tumors in molecular immunohistochemical subtypes, as formerly systematized (Table 6).

Information about complementary radiotherapy was retrieved in 246 patients, most of them (179) received the treatment.

As previously reported, 149 women (50.8\%) underwent neoadjuvant chemotherapy, 104 women (35.4\%) received adjuvant chemotherapy and palliative chemotherapy was prescribed (4.4\%) in 13 cases. Hormonal adjuvant, on the other hand, was prescribed in 159 women (54.2\%).

Oncological outcomes are exhibited in Figure 4, unfortunately standing out the elevated contingent of BC-related deaths.

\section{DISCUSSION}

Breast Cancer in UYW represents a new challenge for physicians, who should be updated on modern biological concepts and latest recommendations for management. A more aggressive tumor behavior has been reported, and ultra-young patients are facing it with family and professional problems, as unique quality of life issues, including loss of fertility, contraception, pregnancy, sexuality, cancer during pregnancy, body image and emotional distress, all of them make the decision to do the treatment complicated ${ }^{7}$. 
A new era of classification criteria has been inaugurated and the term ultra-young come into use. We believe that it is a watershed, but not without constraints, since we consider that defining ultra-young women as those who are 30 years of age or younger would be more useful in clinical practice, as likely they share distinct biological and social particularities. For example, Cancello et al. observed more aggressive cancer phenotypes in women under 30 years, with approximately $75 \%$ of poorly differentiated lesions, compared with $55 \%$ in the group aged $30-34$ years 8 .

Patients under 35 years are known to have a higher rate of locoregional and distant recurrences, entailing elevated mortality.

Several studies have focused on specifically BC in ultrayoung patients, and almost all studies show a worse prognosis ${ }^{8-14}$. According to Han et al. the risk of death has increased by $5 \%$ with a 1-year age reduction for patients $<35$ years. ${ }^{15}$

The most striking result that came out from our data is that, although a relative short-interval follow-up, $25.4 \%$ of the patients evolved to death caused by BC. Xiong et al. at the MD Anderson Cancer Center, in a landmark paper of outcomes in patients diagnosed with $\mathrm{BC}$ before the age of 30 years, revealed 5 -year overall survival rates of $87 \%$ for stage I disease; $60 \%$ for stage II, $42 \%$ for stage III, and $16 \%$ for stage IV ${ }^{12}$. The strength of these results is the impact of late diagnosis in patients portending a worse prognosis due to the tumor aggressiveness.

Hankey et al. highlighted that $0.6 \%$ of the $\mathrm{BC}$ cases were diagnosed in women aged < 30 years in the USA in the 1990s (around 1,200 new cases per year ${ }^{16}$. In the recent years there has been an increase in the cases of $\mathrm{BC}$ in young women ${ }^{17-19}$, leading to an excessive number of loss of lives.

Regrettably, young women tend to be diagnosed at advanced stages, reflecting decreased awareness, lack of screening and fast-growing tumors. Most young patients are diagnosed with a palpable mass. Sole $11.7 \%$ of our patients presented small $\mathrm{T}_{1}$ lesions at the beginning of treatment. At this moment, for a reasonable conjecture, strategies of awareness, and clinical and self-examinations should be implemented in the phase of life when mammography is contraindicated. Obviously, at least for patients with family history of $\mathrm{BC}$, tailored screening measures should be adopted, including echography and magnetic resonance imaging. Moreover, healthy lifestyle should be adopted for every young woman. Indeed, we found out that almost $40 \%$ of our patients presented disproportionate body max index.

Genetic testing in young woman with $\mathrm{BC}$ is strongly recommended regardless of the family history. It is noteworthy that the chance of carrying a germline BRCA $1 / 2$ mutations is at least $10 \%$ in young patients with $\mathrm{BC}$, which is enhanced with a positive

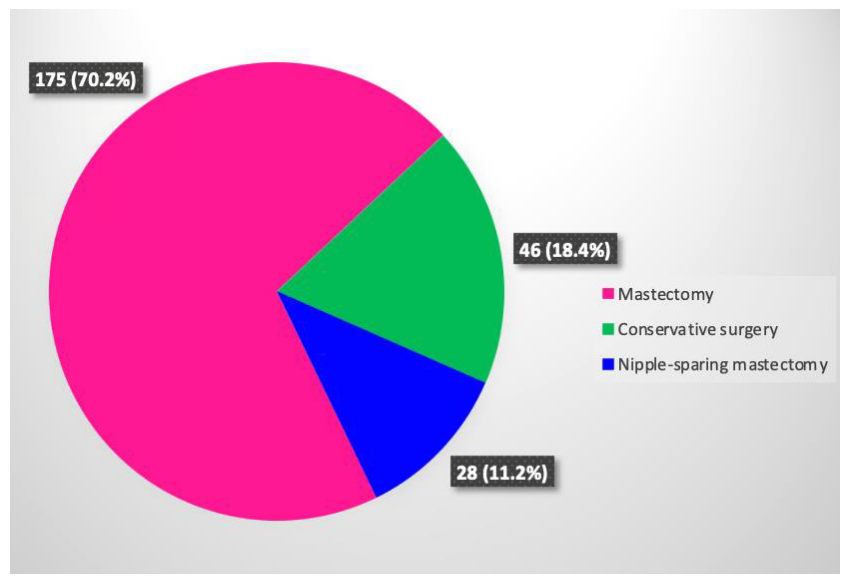

Figure 3. Types of local surgery performed in 249 patients.

Table 3. Frequency and extension of axillary lymph nodes infiltration in 234 patients with available data*.

\begin{tabular}{l|c|c} 
& $\mathbf{n}$ & $\%$ \\
0 & 123 & 52.5 \\
\hline $1-3$ & 59 & 25.2 \\
\hline $4-10$ & 37 & 15.8 \\
\hline$>10$ & $\mathbf{1 5}$ & $\mathbf{6 . 4}$ \\
\hline
\end{tabular}

*Without information: 59.

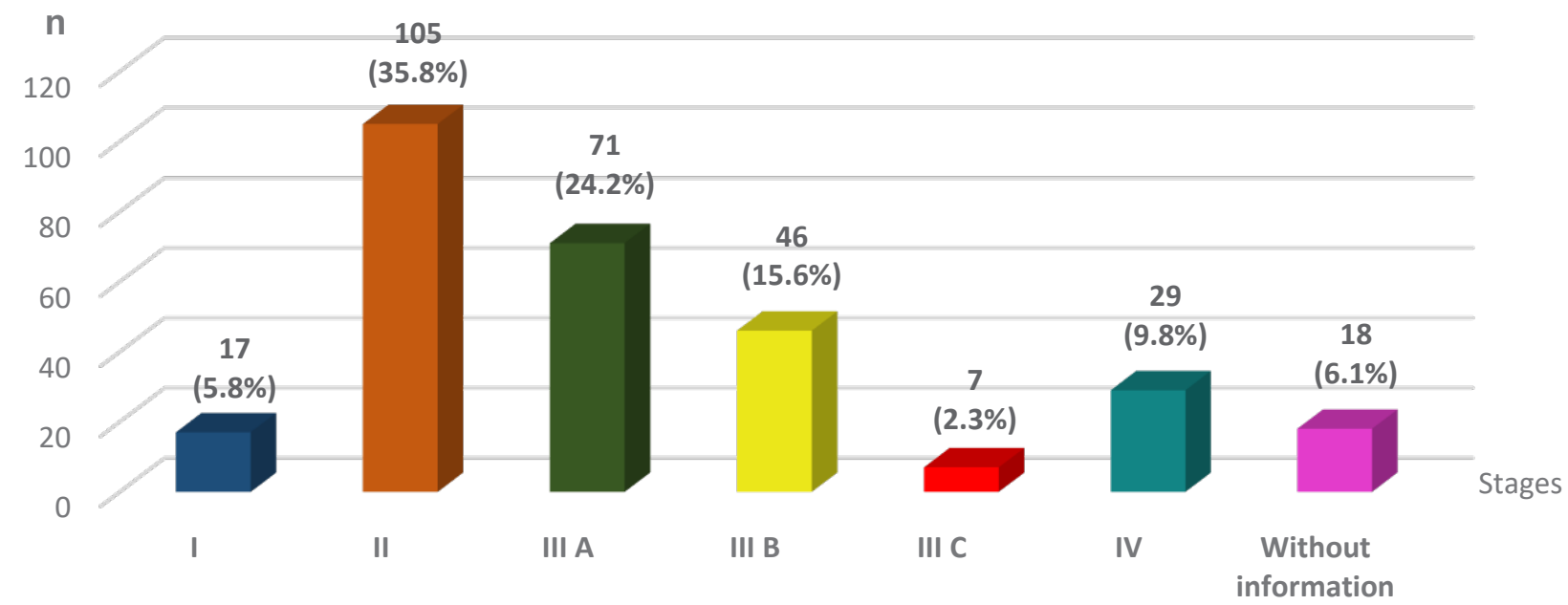

Figure 2. Clinical staging. 
Table 4. Histopathological tumor characteristics.

\begin{tabular}{|c|c|c|}
\hline & $\mathbf{n}$ & $\%$ \\
\hline \multicolumn{3}{|l|}{ pT } \\
\hline$\leq 2 \mathrm{~cm}$ & 84 & 28.6 \\
\hline$>2-\leq 5 \mathrm{~cm}$ & 76 & 26.0 \\
\hline$>5 \mathrm{~cm}$ & 52 & 17.8 \\
\hline complete tumor regression & 25 & 8.5 \\
\hline without information & 56 & 19.1 \\
\hline \multicolumn{3}{|l|}{ Histological grade } \\
\hline I & 9 & 3.0 \\
\hline II & 139 & 47.5 \\
\hline III & 109 & 37.2 \\
\hline without information & 36 & 12.3 \\
\hline \multicolumn{3}{|l|}{ Nuclear grade } \\
\hline 1 & 4 & 1.4 \\
\hline 2 & 92 & 31.3 \\
\hline 3 & 165 & 56.3 \\
\hline without information & 32 & 11.0 \\
\hline \multicolumn{3}{|l|}{ Vascular-lymphatic invasion } \\
\hline Yes & 72 & 24.5 \\
\hline No & 155 & 53.0 \\
\hline without information & 66 & 22.5 \\
\hline \multicolumn{3}{|l|}{ Multicentricity/multifocality } \\
\hline Yes & 31 & 10.5 \\
\hline No & 219 & 74.8 \\
\hline without information & 43 & 14.6 \\
\hline
\end{tabular}

Table 5. Immunohistochemical characteristics.

\begin{tabular}{|c|c|c|}
\hline & n & $\%$ \\
\hline \multicolumn{3}{|l|}{ ER } \\
\hline+ & 191 & 65.2 \\
\hline- & 93 & 31.8 \\
\hline without information & 9 & 3.0 \\
\hline \multicolumn{3}{|l|}{$\mathrm{PgR}$} \\
\hline+ & 168 & 57.3 \\
\hline- & 115 & 39.2 \\
\hline without information & 10 & 3.4 \\
\hline \multicolumn{3}{|l|}{ HER 2} \\
\hline+ & 68 & 23.2 \\
\hline- & 203 & 69.2 \\
\hline without information & 22 & 7.5 \\
\hline \multicolumn{3}{|l|}{$\mathrm{Ki}-67$} \\
\hline$\leq 20 \%$ & 70 & 23.9 \\
\hline $20 \%$ & 180 & 61.4 \\
\hline without information & 43 & 14.7 \\
\hline
\end{tabular}

family history ${ }^{20}$. In cases of negative ER and/or high-grade tumors, the probability reaches $30 \%$. Nevertheless, genetic testing is not available in the Brazilian public health system and its access is also limited in the private healthcare system ${ }^{21}$. Apart from BRCA 1 and 2 mutations, it is important to remember that $\mathrm{BC}$ is one of the most common cancer diagnosed among TP53 mutation carriers (Li-Fraumeni syndrome), and its peak of incidence is under 30 years ${ }^{22}$. In our casuistic view, only 32 cases underwent genetic testing, but predisposing hereditary mutations were identified in 12 patients (37.5\%). Despite the small number of tests, a strong relationship between hereditary background and $\mathrm{BC}$ in UYW was observed.

Due to large tumor size and the immunohistochemical subtyping, more than half of the cases herein described was managed by neoadjuvant treatment (chemotherapy with HER2- targeted therapy when indicated), that entails that a downsizing and a possible complete response could establish a reliable surrogate marker for disease-free survival ${ }^{23}$. Almost $80 \%$ of our cases presented good clinical response (partial or total).

Ideally, the objective of local surgeries in $\mathrm{BC}$ therapy is the complete removal of the malignant cells. In practical terms, it is not totally possible, and there are three main options to be personalized for ipsilateral operation: quadrantectomy, mammary adenectomy and mastectomy, often followed by oncoplastic manoeuvres for partial or total reconstruction.

Many case series have found out that young patients have higher locoregional recurrence rates, which could result in decreased overall survival ${ }^{24-26}$. For Beadle et al. ${ }^{24}$, the best locoregional control was achieved by patients with stage II disease who underwent mastectomy with radiation. Nevertheless, Cancello et al. ${ }^{8}$ showed that the type of surgery performed did not influence

Table 6. Molecular breast cancer subtypes frequency*.

\begin{tabular}{l|c|c} 
& $\mathbf{n}$ & $\%$ \\
\hline Luminal A-like & 32 & 16.7 \\
\hline Luminal B-like/HER 2- & 69 & 35.9 \\
\hline Luminal B-like/HER 2+ & 29 & 15.1 \\
\hline HER 2 overexpressed & 18 & 9.4 \\
\hline Basal like & $\mathbf{4 4}$ & $\mathbf{2 2 . 9}$ \\
\hline
\end{tabular}

*Without information: 101.

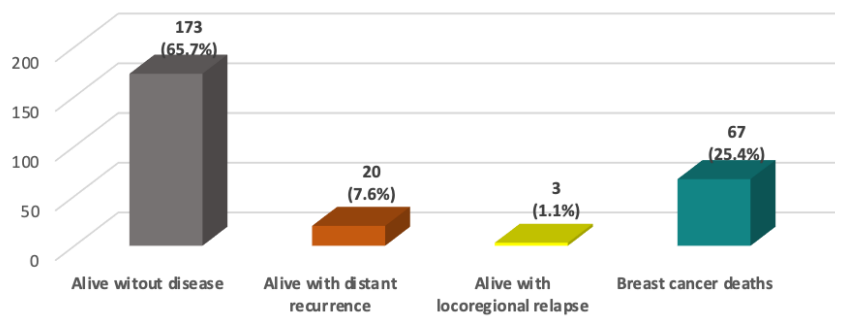

Figure 4. Oncological outcomes in 263 patients with appropriate follow-up information. 
the rates of locoregional relapse. A metanalysis with more than 22,000 young patients ( $\leq 40$ years) demonstrated that quadrantectomy and whole-breast radiotherapy provide overall survival control similar to mastectomy ${ }^{27}$.

There is a concern if these conclusions are valid for UYW and for all molecular subtypes, but we are aware that the prognosis of young woman undergo breast-conserving surgeries have significantly improved compared with two decades ago, as seen by Botteri et al. ${ }^{28}$. Probably, this progress is owing to the policy that younger women do not have smaller volumes of breast tissue removed for cosmetic reasons (clear margins is mandatory), more accurate selection for breast conservation (tumor size, genetic testing and magnetic resonance imaging), and the antiHER2 therapy implementation. Despite these facts, the most of the very young women continue to undergo any form of mastectomy worldwide. The arguments underpinning this conduct in very young patients are: higher risk of heritable abnormalities; more frequent local recurrences; greater life expectancy; higher mortality rate; and the paramount own patient's preference. In general, it seems to be a doctor-patient preference for mastectomy or mammary adenectomy.

The possibility of contralateral prophylactic adenectomy should be considered and accepted to individual practice. There is currently a widespread feeling in favor of bilateral mammary adenectomy in woman aged $\leq 35$ years, reflecting a modern trend ${ }^{29-31}$. While its role is generally accepted in woman with mutated high-risk predisposing genes, Teoh et al. questioned the benefits in women who are just young at presentation or those who have a strong family history, but without demonstrable genetic mutation ${ }^{32}$. They suggest a multidisciplinary tailored approach to support individuals in a shared decision-making process.

Lymph nodal metastases are common in this age range. Ben Abdelkrim et al. ${ }^{9}$, and Alipour et al..$^{33}$ observed involvement in $50 \%$ and $62 \%$ of women aged less than 25 years, whereas we noticed $47.5 \%$. The extension of regional nodes excision should be elected case-by-case.

Our pathological findings were equivalent to those of other case series ${ }^{9,10,34,35}$. The most of our cases were represented by invasive carcinoma (no special type), and infiltrative lobular was very rare. Signals of neoplastic quiescence, such as histological grade I and nuclear grade I, were seen only in 3.5\% and $1.5 \%$. On the other hand, unfavorable immunohistochemical results were common. Negative ER status was observed in almost one third of the patients; negative PgR, in almost 40\%; and Ki-67 > 20\% was impressively common, being identified in more than $60 \%$ of the tumors. A Brazilian study, conducted by Bocchi et al., showed Ki- $67>30 \%$ in $45.5 \%$ of the patients $<44$ years and in $27.6 \%$ of women $\geq 44$ years, and HER 2 overexpression in $23.3 \%$ and $16.8 \%$, respectively, in the same age rangers ${ }^{34}$. For us, HER2 positivity was detected in $25.0 \%$ of the cases with available information.
Breast Cancer is a heterogeneous disease, with several molecular intrinsic subtypes ${ }^{36}$. Basal-like (triple-negative) is more common in young patients, being more likely to be highgrade, and presenting also in this age a worse prognosis ${ }^{37}$. HER2-enriched subtypes, formerly showed poorer outcomes, currently, with HER2 directed therapy, are often associated to better recurrence-free survival. Our case series evidenced high frequency of luminal B and basal-like tumors, and low frequency of luminal A tumors.

An unfavorable landscape was observed in UYW with BC. We found high rate of advanced disease, with adverse pathological and molecular prognostic factors, a few genetic testing and high mortality. BC in young women is an important public health problem, more frequent in Latin American countries than in the USA, with dramatic consequences, as stated by Fidler et al..$^{38}$.

This research has raised many questions which need of further investigation. For changing the present-day scenario, we first need to educate the population, enhancing BC awareness and selfbody attention since adolescence, and stimulating the adoption of a healthy life styl $\mathrm{e}^{39}$. In the study of Ogawa et al., about a breast self-examination in Japan, the average size of tumor was $2.5 \mathrm{~cm}$ at diagnosis for who performed it monthly, compared to $3.5 \mathrm{~cm}$ for those who did not ${ }^{40}$. A shift of this size is expected to result in a survival difference of at least $15 \%{ }^{39}$. Self-examination practice in young women who did not undergo mammographic screening merits deeper consideration. On the other hand, appropriate and more efficient therapy is needed, taking into consideration modern strategies of precision therapy to improve outcomes. Tailored treatments offered by committed and skilled multidisciplinary teams are crucial to achieve the best holistic results when caring for the youngest women with BC.

\section{AUTHORS' CONTRIBUTIONS}

A.M.: Formal Analysis, Project administration, Software.

A.Y.: Formal Analysis, Project administration, Software.

C.F.: Investigation, Data curation.

E.P.: Investigation, Data curation.

F.A.: Investigation, Data curation.

G.T.: Investigation, Data curation.

H.V.: Investigation, Data curation.

K.C.: Investigation, Data curation.

I.Jr.: Investigation, Data curation.

J.B.: Investigation, Data curation.

J.F.: Investigation, Data curation.

L.G.: Investigation, Data curation.

M.P.: Investigation, Data curation.

R.V.: Investigation, Data curation.

T.D.: Investigation, Data curation.

V.Jr.: Investigation, Data curation.

A.B.: Conceptualization, Supervision, Writing - first draft. 
1. Assi HA, Khoury KE, Dbouk H, Khalil LE, Mouhieddine TH, El Saghir NS. Epidemiology and prognosis of breast cancer in young women. J Thorac Dis. 2013;5(Suppl. 1):S2-8. https://doi. org/10.3978/j.issn.2072-1439.2013.05.24

2. Wei XQ, Li X, Xin XJ, Tong ZS, Zhang S. Clinical features and survival analysis of very young (age<35) breast cancer patients. Asian Pac J Cancer Prev 2013;14(10):5949-52. https:// doi.org/10.7314/apjcp.2013.14.10.5949

3. Liu Z, Sahli Z, Wang Y, Wolff AC, Cope LM, Umbricht CB. Young age at diagnosis is associated with worse prognosis in the Luminal A breast cancer subtype: a retrospective institutional cohort study. Breast Cancer Res Treat 2018;172(3):689-702. https://doi.org/10.1007/s10549-018-4950-4

4. Partridge AH, Pagani O, Abulkhair O, Aebi S, Amant F, Azim Jr. HÁ, et al. First international consensus guidelines for breast cancer in young women (BCY1). Breast. 2014;23(3):209-20. https://doi.org/10.1016/j.breast.2014.03.011

5. Reyna C, Lee MC. Breast cancer in young women: special considerations in multidisciplinary care. J Multidiscip Health. 2014;2014(7):419-29. https://doi.org/10.2147/jmdh.s49994

6. Goldhirsch A, Winer EP, Coates AS, Gelber RD, PiccartGebhardt M, Thürlimann B, et al. Personalizing the treatment of women with early breast cancer: highlights of the St Gallen International Expert Consensus on the primary therapy of early breast cancer 2013. Ann Oncol. 2013;24(9):2206-23. https://doi.org/10.1093/annonc/mdt303

7. Cancello G, Montagna E. Treatment of breast cancer in young women: do we need more aggressive therapies? J Thorac Dis. 2013;5(Suppl. 1):S47-54. https://doi.org/10.3978/j.issn.20721439.2013.06.10

8. Cancello G, Maisonneuve P, Mazza M, Montagna E, Rotmensz N, Viale G, et al. Pathological features and survival outcomes of very young patients with early breast cancer: how much is "very young"? Breast. 2013;22(6):1046-51. https://doi. org/10.1016/j.breast.2013.08.006

9. Ben Abdelkrim S, Fathallah K, Rouatbi R, Ayachi M, Hmissa S, Mokni M. OM.breast cancer in very young women aged 25 year-old or below in the center of Tunisia and review of the literature. Pathol Oncol Res. 2015;21(3):553-61. https://doi. org/10.1007/s12253-015-9944-5

10. Dimitrakakis C, Tsigginou A, Zagouri F, Marinopoulo S, Sergentanis TN, Keramopoulos A, et al. Breast cancer in women aged 25 years and younger. Obstet Gynecol. 2013;121(6):123540. https://doi.org/10.1097/aog.0b013e318291ef9a

11. Yao S, Xu B, Ma F, Liao Y, Fan Y. Breast cancer in women younger than 25: clinicopathological features and prognostic factors. Ann Oncol. 2009;20(2):387-9. https://doi.org/10.1093/annonc/mdn711

12. XiongQ,Valero V,KauV,KauS-W,TaylorS, Smith TL, etal.Female patients with breast carcinoma age 30 years and younger have a poor prognosis: the M.D. Anderson Cancer Center experience. Cancer. 2001;92(10):2523-8. https://doi.org/10.1002/10970142(20011115)92:10<2523::aid-cncr1603>3.0.co;2-6

13. Anderson BO, Senie RT, Vetto JT, Wong GY, McCormick B, Borgen PI. Improved survival in young women with breast cancer. Ann Surg Oncol. 1995;2(5):407-15. https://doi. org/10.1007/bf02306373
14. Chung WP, Lee KT, Chen YP, Hsu Y-T, Loh Z-J, Huang C-C, et al. The prognosis of early-stage breast cancer in extremely young female patients. Medicine (Baltimore). 2021;100(1):e24076. https://doi.org/10.1097/md.0000000000024076

15. Han W, Kang SY, Korean Breast Cancer Society. Relationship between age at diagnosis and outcome of premenopausal breast cancer: age less than 35 years is a reasonable cut-off for defining young age-onset breast cancer. Breast Cancer Res Treat. 2010;119(1):193-200. https://doi.org/10.1007/ s10549-009-0388-Z

16. Hankey BF, Miller B, Curtis R, Kosary C. Trends in breast cancer in younger women in contrast to older women. J Natl Cancer Inst Monogr. 1994(16):7-14.

17. Lee HB, Han W. Unique features of young age breast cancer and its management. J Breast Cancer. 2014;17(4):301-7. https:// doi.org/10.4048/jbc.2014.17.4.301

18. Gabriel CA, Domchek SM. Breast cancer in young women. Breast Cancer Res. 2010;12(5):212. https://doi.org/10.1186/ bcr2647

19. Anastasiadi Z, Lianos GD, Ignatiadou E, Harissis HV, Mitsis M. Breast cancer in young women: an overview. Updates Surg. 2017;69(3):313-7. https://doi.org/10.1007/s13304-017-0424-1

20. Villarreal-Garza C, Weitzel JN, Llacuachaqui M, Sifuentes E, Magallenes-Hoyos MC, Gallardo L, et al. The prevalence of BRCA1 and BRCA2 mutations among young Mexican women with triple-negative breast cancer. Breast Cancer Res Treat. 2015;150(2):389-94. https://doi.org/10.1007/s10549-015-3312-8

21. Achatz MI, Caleffi M, Guindalini R, Marques RM, NogueiraRodrigues A, Ashton-Prolla P. Recommendations for advancing the diagnosis and management of hereditary breast and ovarian cancer in Brazil. JCO Glob Oncol. 2020;(6):439-52. https://doi.org/10.1200/jgo.19.00170

22. Bouaoun L, Sonkin D, Ardin M, Hollstein M, Byrnes G, Zavadil J, et al. TP53 variations in human cancers: new lessons from the IARC TP53 database and genomics data. Hum Mutat. 2016;37(9):865-76. https://doi.org/10.1002/humu.23035

23. Spring L, Greenup R, Niemierko A, Schapira L, Haddad S, Jimenez R, et al. Pathologic complete response after neoadjuvant chemotherapy and long-term outcomes among young women with breast cancer. J Natl Compr Canc Netw. 2017;15(10):1216-23. https://doi.org/10.6004/jnccn.2017.0158

24. Beadle BM, Woodward WA, Tucker SL, Outlaw ED, Allen PK, $\mathrm{Oh} \mathrm{JL}$, et al. Ten-year recurrence rates in young women with breast cancer by locoregional treatment approach. Int J Radiat Oncol Biol Phys. 2009;73(3):734-44. https://doi.org/10.1016/j. ijrobp.2008.04.078

25. Kim SH, Simkovich-Heerdt A, Tran KN, Maclean B, Borgen PI. Women 35 years of age or younger have higher locoregional relapse rates after undergoing breast conservation therapy. J Am Coll Surg. 1998;187(1):1-8. https://doi.org/10.1016/s10727515(98)00114-8

26. Ordu C, McGuire K, Alco G, Pilanci KN, Koksal UI, Elbüken F, et al. The prognostic impact of molecular subtypes and very young age on breast conserving surgery in early stage breast cancer. Cureus. 2016;8(6):e633. https://doi.org/10.7759/ cureus.633 
27. Vila J, Gandini S, Gentilini O. Overall survival according to type of surgery in young ( $\leq 40$ years) early breast cancer patients: a systematic meta-analysis comparing breast-conserving surgery versus mastectomy. Breast. 2015;24(3):175-81. https:// doi.org/10.1016/j.breast.2015.02.002

28. Botteri E, Veronesi P, Vila J, Rotmensz N, Galimberti V, Thomazini MV, et al. Improved prognosis of young patients with breast cancer undergoing breast-conserving surgery. Br J Surg. 2017;104(13):1802-10. https://doi.org/10.1002/bjs.10658

29. Lazow SP, Riba L, Alapati A, James TA. Comparison of breastconserving therapy vs mastectomy in women under age 40: national trends and potential survival implications. Breast J. 2019;25(4):578-84. https://doi.org/10.1111/tbj.13293

30. BarrosA,CarvalhoHA,AndradeFEM,NimirCCBA,SampaioMMC, Makdissi FB, et al. Mammary adenectomy followed by immediate reconstruction for treatment of patients with early-infiltrating breast carcinoma: a cohort study. Sao Paulo Med J. 2019;137(4):33642. https://doi.org/10.1590/1516-3180.2018.0356220719

31. Hyder Z, Harkness EF, Woodward ER, Bowers NL, Pereira M, Wallace AJ, et al. Risk of contralateral breast cancer in women with and without pathogenic variants in BRCA1, BRCA2, and TP53 genes in women with very early-onset (<36 Years) breast cancer. Cancers (Basel). 2020;12(2):378. https://doi.org/10.3390/cancers12020378

32. Teoh V,Tasoulis MK, Gui G. Contralateral prophylactic mastectomy inwomen with unilateralbreastcancer whoare genetic carriers, have a strong family history or are just young at presentation. Cancers (Basel). 2020;12(1):140. https://doi.org/10.3390/cancers12010140

33. Alipour S, Omranipour R, Jahanzad I, Bagheri K. Very young breast cancer in a referral center in Tehran, Iran; review of 55 cases aged 25 or less throughout 33 years. Asian Pac J Cancer Prev. 2013;14(11):6529-32. https://doi.org/10.7314/apjcp.2013.14.11.6529
34. Bocchi M, Pereira NS, Furuya RK, Fernandes CYM, LosiGuembarovski R, Vitiello GAF, et al. Expression of Ki67 and p53 proteins: breast cancer aggressivity markers in Brazilian young patients. J Adolesc Young Adult Oncol. 2021;10(4). https://doi.org/10.1089/jayao.2020.0037

35. Copson E, Eccles B, Maishman T, Gerty S, Stanton L, Cutress RI, et al. Prospective observational study of breast cancer treatment outcomes for UK women aged 18-40 years at diagnosis: the POSH study. J Natl Cancer Inst. 2013;105(13):97888. https://doi.org/10.1093/jnci/djt134

36. Sorlie T, Perou CM, Tibshirani R, Aas T, Geisler S, Johnsen $\mathrm{H}$, et al. Gene expression patterns of breast carcinomas distinguish tumor subclasses with clinical implications. Proc Natl Acad Sci U S A. 2001;98(19):10869-74. https://doi. org/10.1073/pnas.191367098

37. Alabdulkareem H, Pinchinat T, Khan S, Landers A, Christos $\mathrm{P}$, Simmons R, et al. The impact of molecular subtype on breast cancer recurrence in young women treated with contemporary adjuvant therapy. Breast J. 2018;24(2):148-53. https://doi.org/10.1111/tbj.12853

38. Fidler MM, Gupta S, Soerjomataram I, Ferlay J, SteliarovaFoucher E, Bray F. Cancer incidence and mortality among young adults aged 20-39 years worldwide in 2012: a populationbased study. Lancet Oncol. 2017;18(12):1579-89. https://doi. org/10.1016/s1470-2045(17)30677-0

39. Narod SA. Breast cancer in young women. Nat Rev Clin Oncol. 2012;9(8):460-70. https://doi.org/10.1038/ nrclinonc.2012.102

40. Ogawa H, Tominaga S, Yoshida M, Kubo K, Takeuchi S. Breast self-examination practice and clinical stage of breast cancer. Jpn J Cancer Res. 1987;78(5):447-52. 